e-Journal Keperawatan (e-Kp), Volume 7 Nomor 1, Mei 2019

\title{
HUBUNGAN KECERDASAN SPIRITUAL DENGAN PERILAKU ALTRUISTIK PADA MAHASISWA KEPERAWATAN UNIVERSITAS SAM RATULANGI MANADO
}

\author{
Indriyani Diyai \\ Hendro Bidjuni \\ Franly Onibala \\ Program Studi Ilmu Keperawatan Fakultas \\ Kedokteran Universitas Sam Ratulangi Manado \\ Email: indridiyai21@gmail.com
}

\begin{abstract}
Altruistic behavior is a voluntary act of helping others without expecting any reward, one factor that influence the altruistic is religious and moral values. To develop religious and moral values, college student need to have high spiritual intelligence. The Research Purpose is to identify the spiritual intelligence and altruistic behavior as well as to analyze whether there is any relation of spiritual intelligence to altruistic behavior of nursing student of Sam Ratulangi university Manado. The Research Design used is Descriptive Analysis method through Cross-Sectional. The sample consists of 73 respondents obtained by using non random sampling technique with dengan total sampling method. The Result of the Research significant result was obtained at $\rho=0,000<\alpha(0,05)$ and coefficient correlation $(r)=0,693$. The Conclusion is there is a positive and significant relation of spiritual intelligence with altruistic behavior of college student, the higher the spiritual intelligence, the greater the altruistic behavior of nursing student of Sam Ratulangi university Manado
\end{abstract}

Keyword: Spiritual Intelligence and Altruistik Behavior, Adolescent, College Student

\begin{abstract}
Abstrak: Perilaku Altruistik adalah tindakan sukarela yang dilakukan oleh seseorang untuk menolong orang lain tanpa mengharapkan imbalan apa pun, salah satu faktor yang mempengaruhi tindakan altruistik yaitu nilai-nilai agama dan moral. Untuk mencapai perkembangan nilai-nilai agama dan moral, mahasiswa perlu memiliki kecerdasan spiritual yang tinggi. Tujuan penelitian ini mengidentifikasi kecerdasan spiritual dan perilaku altruistik pada mahasiswa serta menganalisis apakah ada hubungan kecerdasan spiritual dengan perilaku altruistik pada mahasiswa keperawatan Universitas Sam Ratulangi Manado. Desain penelitian yang digunakan yaitu Deskriptif Analitik dengan pendekatan Cross Sectional. Sampel berjumlah 73 responden yang didapat dengan menggunakan tehnik non random sampling dengan metode total sampling. Hasil penelitian didapatkan nilai signifikan $\rho=0,000<\alpha(0,05)$ dan koefisien korelasi $(\mathrm{r})=0,693$ Kesimpulan adanya hubungan yang positif dan signifikan antara kecerdasan spiritual dengan perilaku altruistik pada mahasiswa, semakin tinggi tingkat kecerdasan spiritual, semakin tinggi pula tingkat perilaku altruistik mahasiswa keperawatan Universitas Sam Ratulangi
\end{abstract}

Kata Kunci : Kecerdasan Spiritual, Perilaku Altruistik, Remaja, Mahasiswa 


\section{PENDAHULUAN}

Manusia merupakan makhluk sosial yang diciptakan untuk berdampingan dengan orang lain dan tidak bisa hidup secara individual. Sebagai makhluk sosial, hendaknya manusia saling tolong menolong satu sama lain dan mengadakan interaksi dengan orang lain untuk bertukar pikiran serta untuk memenuhi kebutuhan hidupnya. Memberikan bantuan ataupun keuntungan pada orang lain tanpa mengharap imbalan apapun dalam psikologi disebut dengan altruisme (Andromeda, 2014). Bangsa Indonesia memegang teguh altruisme namun, dengan munculnya modernisasi dan globalisasi memberikan dampak yang besar dalam kehidupan manusia, saat ini banyak individu yang lebih mementingkan dirinya sendiri dan berkurangnya rasa tolong menolong antar sesama yang berakibat pada munculnya sifat individualisme. Individualisme ini merupakan faham yang bertitik tolak dari sikap egoisme, mementingkan dirinya sendiri sehingga mengorbankan orang lain demi kepentingan dirinya sendiri, tanpa terkecuali mahasiswa (Arif, 2010).

Mahasiswa sebagai calon intelektual muda yang sedang mengalami proses belajar dituntut untuk memiliki tanggung jawab dalam bertingkah laku sesuai dengan norma masyarakat, berintelektual tinggi, dan dapat memberikan contoh yang baik pada masyarakat - Selain di masyarakat, lingkungan di mana mahasiswa tersebut kuliah juga mengharapkan hal serupa dengan yang diharapkan pada masyarakat. Salah satu perilaku mahasiswa yang diharapkan dapat tumbuh dan berkembang optimal adalah perilaku altruisme. (Fatimah, 2015). Seiring dengan berjalannya waktu, kepedulian mahasiswa terhadap orang lain dan lingkungan disekitar semakin menurun. Dapat dikatakan bahwa mahasiswa lebih menggunakan konsep hidup menyenangkan diri sendiri dahulu baru orang lain. Hal tersebut berdasarkan contoh kasus pada jurnal dari penelitian yang dilakukan oleh Lensus (2015) mengatakan bahwa remaja saat ini lebih berkarakter egois dengan lingkungan sekitar karena telah mengikuti perkembangan jaman yang canggih, yaitu ponsel dan media sosial yang lain. Dari hasil observasi dan penelitian yang ia lakukan, ia menarik kesimpulan bahwa para mahasiswa dan mahasiswi pengguna ponsel mempunya sikap kurang peduli terhadap lingkungan sosial dilingkup kampus. Dalam penelitian yang ia lakukan terhadap para mahasiswa dan mahasiswi pengguna ponsel, sikap kurang peduli terhadap lingkungan sosial. Selain itu, berdasarkan penelitian yang dilakukan oleh Sulawati (2017) yang berjudul Perilaku Altruis Relawan Organisasi AbdA di Tinjau dari Tingkat EQ dan SQ ditemukan bahwa mahasiswa enggan menolong orang lain yang tidak dikenal, lebih berkumpul dengan sahabat dan teman sesuai dengan daerah asal, lebih senang bekerja sendiri, dan tidak berkenan bermurah hati dalam hal materi.

Menurut Widyastuti (2014) ada beberapa faktor yang mempengaruhi altruisme, salah satunya adalah nilai-nilai agama dan moral, maksudnya seseorang yang menolong sangat tergantung dari penghayatan terhadap nilai-nilai agama dan moral yang mendorong seseorang dalam melakukan pertolongan. Kecerdasan spiritual menurut Zohar (2007) adalah kecerdasan untuk menghadapi dan memecahkan persoalan makna dan nilai yaitu kecerdasan untuk menempatkan perilaku dan hidup kita dalam konteks dan makna yang lebih luas dan kaya, kecerdasan untuk menilai bahwa tindakan atau jalan hidup seseorang lebih bermakna dibandingkan dengan yang lainnya. Menurut Rudyanto (2010), Seseorang dengan kecerdasan spiritual tinggi, maka akan mengembalikan segala perbuatannya kepada Tuhan sehingga perbuatan dan perilakunya menjadi bermakna dalam hidupnya. Dengan demikian, seseorang mampu memaknai perbuatan dan perilaku prososialnya sebagai wujud ibadah kepada Tuhan dalam mewujudkan sikap tolong menolong dan cinta kasih terhadap sesama.

Studi awal yang dilakukan peneliti terhadap 5 Mahasiswa, Mahasiswa mangatakan lebih sering berkumpul dengan sahabat masingmasing. Selain itu Mahasiswa mengatakan hanya akan menolong orang yang dikenalnya, mengaku sulit menolong orang yang tidak dikenal, dan tidak akan menolong jika sedang sibuk. Berdasarkan telaah literatur diatas, maka penulis tertarik untuk melakukan penelitian dengan judul hubungan kecerdasan spiritual dengan perilaku altruistik pada mahasiswa Keperawatan Universitas Sam Ratulangi Manado.

\section{METODE PENELITIAN}


Jenis penelitian ini adalah penelitian kuantitatif menggunakan rancangan desain penelitian Analitik dengan pendekatan Cross Sectional. Penelitian ini memiliki variabel independen yaitu kecerdasan spiritual dan variabel dependen yaitu perilaku altruistik pada mahasiswa Keperawatan Universitas Sam Ratulangi Manado. Populasi dalam penelitian ini adalah mahasiswa semester III Keperawatan Universitas Sam Ratulangi Manado yang berjumlah 69 orang. Pengambilan sampel dalam penelitian ini dilakukan secara non random sampling dengan metode total sampling sehingga semua populasi digunakan sebagai sampel yaitu sebanyak 69 orang.

Instrumen yang digunakan adalah kuesioner. Kuesioner kecerdasan spiritual yang pernah digunakan oleh Rudyanto (2010) yang terdiri dari 18 pertanyaan, skor nilai menggunakan skala likert dengan pilihan jawaban sangat setuju skor 4, setuju skor 3, tidak setuju 2, dan sangat tidak setuju skor 1 . Sedangkan untuk kuesioner perilaku altruistik pernah digunakan oleh Utomo (2013) yang terdiri dari 22 pertanyaan skor nilai menggunakan skala likert dengan pilihan jawaban sangat setuju skor 4, setuju skor 3, tidak setuju 2, dan sangat tidak setuju skor 1 . Prosedur pengolahan data yang dilakukan melalui tahap editing, coding, cleaning, dan tabulating. Analisa data yang dilakukan meliputi analisa univariat yang menghasilkan distribusi frekuensi berdasarkan presentase dari tiap-tiap karakteristik variabel dan analisa bivariat digunakan untuk mengetahui hubungan antara dua variabel dengan menggunakan adalah uji spearman correlation dengan tingkat kemaknaan 95\% $(\alpha=0,05)$ (Sujarweni,2015).

\section{HASIL dan PEMBAHASAN}

Tabel 1. Distribusi Frekuensi berdasarkan usia

\begin{tabular}{ccc}
\hline Usia & $\mathbf{n}$ & $\mathbf{( \% )}$ \\
\hline 18 & 12 & 17,4 \\
19 & 52 & 75,4 \\
20 & 5 & 7,2 \\
\hline total & 69 & 100 \\
\hline
\end{tabular}

Sumber: Data Primer 2019

Hasil analisa tabel 1 menunjukkan bahwa dari 69 responden didapatkan sebagian besar responden berusia 19 tahun sebanyak 52 responden $(75,4 \%)$. Usia ini tergolong pada usia remaja akhir. Hal ini disebabkan karena masa remaja akhir merupakan masa transisi antara kanak-kanak dan masa dewasa yang menuntut remaja untuk meningkatkan kemandirian, mengemban tanggung jawab yang lebih besar dan peran yang penting dalam lingkungan mereka (Aswandi, 2017). Renata (2016) menyatakan bahwa seseorang yang berada pada masa remaja akhir umumnya berada pada tingkat pendidikan formal di perguruan tinggi. Pada usia ini, mahasiswa diharapkan telah mencapai kematangan moral. Individu yang telah mencapai kematangan moral tidak saja menghindari perilaku negatif, tetapi juga dapat memotivasi untuk berperilaku positif seperti dapat berempati, peduli, toleransi, bekerjasama, termasuk berperilaku altruistik.

Tabel 2. Distribusi Frekuensi berdasarkan jenis kelamin

$\begin{array}{lll}\text { Jenis } & \text { n } & (\%)\end{array}$

\section{Kelamin}

\begin{tabular}{ccc}
\hline Laki-Laki & 6 & 8,7 \\
Perempuan & 63 & 91,3 \\
\hline Total & 69 & 100 \\
\hline
\end{tabular}

\section{Sumber: Data Primer 2019}

Hasil analisa tabel 2 menunjukkan bahwa dari 69 responden didapatkan sebagian besar responden berjenis kelamin perempuan sebanyak 63 responden (91,3\%). Harjo (2018) juga menyatakan bahwa perempuan lebih mudah untuk merasakan iba pada orang lain serta lebih melibatkan emosi dibandingkan laki-laki dan juga perempuan lebih bersedia menolong siapapun yang membutuhkan tanpa harus diminta dibandingkan laki-laki. Syarif (2015) mengatakan bahwa beberapa penelitian menunjukkan bahwa anak perempuan lebih banyak menunjukkan perilaku menolong dan empati terhadap orang lain, dibandingkan anak laki-laki. 
Tabel 3. Distribusi Frekuensi Kecerdasan Spiritual

\begin{tabular}{ccc}
\hline $\begin{array}{c}\text { Kecerdasan } \\
\text { spiritual }\end{array}$ & $\mathbf{n}$ & $\mathbf{( \% )}$ \\
\hline Rendah & 6 & 8,7 \\
Sedang & 49 & 71 \\
Tinggi & 14 & 20,3 \\
\hline Total & 69 & 100 \\
\hline
\end{tabular}

Sumber: Data Primer 2019

Hasil analisa tabel 3 menunjukkan bahwa mahasiswa keperawatan Universitas Sam Ratulangi Manado sebagian besar memiliki tingkat kecerdasan spiritual sedang sebanyak 49 responden $(71 \%)$. Hasil penelitian ini sejalan dengan penelitian yang dilakukan Sulawati (2017) yaitu mahasiswa yang memiliki kecerdasan spiritual tinggi, sebanyak 19 orang (54\%) kecerdasan spiritual sedang, dan sebanyak 8 orang $(23 \%)$ memiliki kecerdasan spiritual rendah. Kecerdasan spiritual merupakan faktor penting remaja dalam membentuk diri yang berkarakter dan peduli dengan orang lain. Seseorang yang memiliki kecerdasan spiritual yang tinggi menjadikan individu tersebut mampu untuk mencari makna dalam hidupnya, dan terjadinya kelangsungan hidup yang harmonis (Arifah,2018).

Tabel 4. Distribusi Frekuensi Perilaku Altruistik

\begin{tabular}{ccc}
\hline Perilaku Altruistik & $\mathbf{n}$ & $\mathbf{( \% )}$ \\
\hline Rendah & 12 & 17,4 \\
Sedang & 45 & 65,2 \\
Tinggi & 12 & 17,4 \\
\hline Total & 69 & 100 \\
\hline
\end{tabular}

\section{Sumber: Data Primer 2019}

Hasil analisa tabel 4 menunjukkan bahwa mahasiswa keperawatan Universitas Sam Ratulangi Manado sebagian besar memiliki tingkat perilaku altruistik sedang sebanyak 45 responden $(65,2 \%)$. Hasil penelitian ini sejalan dengan penelitian yang dilakukan oleh Alam (2014) yang menunjukkan bahwa mahasiswa yang memiliki tingkat perilaku altruistik tinggi yaitu sebanyak 11 orang (15\%), tingkat perilaku altruistik sedang yaitu sebanyak 52 orang $(71,23 \%)$, dan tingkat perilaku altruistik rendah yaitu sebanyak 10 orang $(13,70 \%)$.

Tabel 5. Hubungan Kecerdasan Spiritual dengan Perilaku Altruistik pada Mahasiswa Keperawatan Universitas Sam Ratulangi Manado

\begin{tabular}{|c|c|c|c|c|c|c|c|c|c|}
\hline & \multicolumn{7}{|c|}{ Perilaku Altruistik } & \multirow{3}{*}{$\mathrm{p}$} & \multirow{3}{*}{$\mathrm{r}$} \\
\hline & \multicolumn{2}{|c|}{$\underline{\text { Rendah }}$} & \multicolumn{2}{|c|}{ Sedang } & \multicolumn{2}{|c|}{ Tinggi } & \multirow{2}{*}{$\begin{array}{r}\text { Total } \\
\mathrm{N} \\
\end{array}$} & & \\
\hline & $\mathrm{n}$ & $\%$ & $\mathrm{n}$ & $\%$ & $\mathrm{n}$ & $\%$ & & & \\
\hline Rendah & 4 & 5,8 & 2 & 2,9 & 0 & 0 & 6 & 0,000 & 0,693 \\
\hline Sedang & 8 & 11,6 & 37 & 53,6 & 4 & 5,8 & 49 & & \\
\hline Tinggi & 0 & 0 & 6 & 8,7 & 8 & 11,6 & 14 & & \\
\hline Total & 12 & 17,4 & 45 & 65,2 & 12 & 17,4 & 69 & & \\
\hline
\end{tabular}

Sumber: Data Primer 2019

Hasil analisa tabel 5 dengan menggunakan uji spearman korelasi diketahui nilai signifikan sebesar $0,000(\mathrm{p}<0,05$ dengan koefisien korelasi Spearman (r) sebesar 0,693 yang menunjukkan adanya hubungan yang positif dan signifikan antara kecerdasan spiritual dengan perilaku altruistik pada mahasiswa keperawatan Universitas Sam Ratulangi Manado. Dengan demikian, dapat disimpulkan semakin tinggi tingkat kecerdasan spiritual maka semakin tinggi pula tingkat perilaku altruistik mahasiswa keperawatan Universitas Sam Ratulangi Manado.

Penelitian ini sejalan dengan penelitian yang dilakukan oleh Wulandari (2011) yang berjudul hubungan antara kecerdasan spiritual dengn altruisme pada anggota komunitas San't Egidio Yogyakarta, diperoleh nilai signifikan sebesar 0,011 ( $\mathrm{p}<0,05)$ yang menunjukkan adanya hubungan yang positif antara kecerdasan spiritual dengan altruisme anggota komunitas San't Egidio Yogyakarta. Penelitian lain yang dilakukan oleh Alam (2014) yang berjudul hubungan kecerdasan spiritual dengan altruisme mahasiswa fakultas psikologi UIN Maulana Malik Ibrahim Malang, diperoleh nilai signifikan sebesar $0,000(p<0,05)$ dengan koefisien korelasi spearman ( $r$ ) sebesar 0,876 juga menunjukkan adanya hubungan yang signifikan dan positif antara kecerdasan spiritual dan altruisme. Myers ( 2012) yang mengatakan bahwa ada beberapa faktor yang mempengaruhi altruisme, salah satunya yaitu nilai-nilai agama dan moral, maksudnya seseorang yang menolong sangat tergantung dari penghayatan 
terhadap nilai- nilai agama dan moral yang mendorong seseorang dalam melakukan pertolongan. Hal ini juga dinyatakan oleh Alam (2014) terdapat tiga bagian untuk menguji tingkat kecerdasan spiritual, salah satunya adalah dari sudut pandang relasi sosialkeagamaan, artinya konsekwensi psikologis spiritual- keagamaan terhadap sikap sosial yang menekankan segi kebersamaan dan kesejahteraan sosial. Kecerdasan spiritual

akan tercermin pada ikatan kekeluargaan antar sesama, peka terhadap kesejahteraan orang lain dan makhluk hidup lain, bersikap dermawan.

\section{SIMPULAN}

Berdasarkan hasil penelitian, maka kesimpulan bahwa terdapat hubungan yang positif dan signifikan antara kecerdasan spiritual dengan perilaku altruistik pada mahasiswa. Dengan demikian, semakin tinggi tingkat kecerdasan spiritual maka semakin tinggi pula tingkat perilaku altruistik mahasiswa keperawatan Universitas Sam Ratulangi Manado.

\section{DAFTAR PUSTAKA}

Alam, Muhammad S. (2014). Hubungan antara Kecerdasan Spiritual dengan Altruisme pada Mahasiswa Fakultas Psikologi UIN Maulana Malik Ibrahim Malang. Skripsi. Malang: Universitas Islam Negeri Maulana Malik Ibrahim.

Andromeda, S. (2014). Hubungan antara Empati dengan Perilaku altruisme pada Karang Truna Desa Pakang. http://eprints.ums.ac.id/30704/14.NAS KAH_PUBLIKASI.pdf. Diakses pada tanggal 28 November 2018

Arif, Ahmad. (2010). Hubungan antara Kecerdasan Emosi dengan Intensi Altruisme pada Siswa SMA $N 1$ Tahunan Jepara. Skripsi. Surakarta: Universitas Muhammadiyah Surakarta

Arifah, Anida. (2018). Hubungan antara Kecerdasan Spiritual dengan Perilaku Prososial pada Remaja. http://eprints.ums.ac.id/65835/1/NASK AH\%2520PUBLIKASI.pdf. Diakses pada tanggal 3 Maret 2019
Aswandi, Fitri. (2017). Hubungan Kecerdasan Spiritual dengan Tingkat Stress pada Mahasiswa Keperawatan Universitas Tanjungpura Pontianak. http://jurnal.untan.ac.id/index.php/jmkep erawatanFK/article/download. Diakses pada tanggal 3 Maret 2019

Fatimah, Siti. (2015). Hubungan antara Empati dengan Perilaku altruisme pada Mahasiswa Psikologi Universitas Muhammadiyah Surakarta.Skripsi. Surakarta: Universitas Muhammadiyah Surakarta

Harjo, Inggrita Laurenza. (2018). Perbedaan Altruisme Berdasarkan Jenis Kelamin pada Relawan di Sanggar Alang-Alang Surabaya.

https://jurnalmahasiswa.unesa.ac.id/inde x.php/character/article/view/25406.

Diakses pada 3 Maret 2019

Lensus, Eva Nuari. (2015). Perilaku Prososial pada Mahasiswa. https://studylibid.com/doc/794882/251. Diakses pada tanggal 2 Desember 2018

Myers, David G. (2012). Psikologi Sosial jilid 2. Jakarta: Salemba Humanika

Renata, S dan Permitasari, D. (2016). Perilaku Prososial pada Mahasiswa Ditinjau dari Jenis Kelamin dan Tipe Kepribadian. http://journal.unika.ac.id/index.php/psi/a rticle/download. Diakses pada 2 Maret 2019

Rudyanto, E. (2010). Hubungan Kecerdasan Emosi dan Kecerdasan Spiritual dengan Perilaku Prososial pada Perawat. Skripsi. Surakarta: Universitas Sebelas Maret

Sujarweni, V.W. (2015). Statistika Untuk Kesehatan. Yogyakarta : Gava Madia

Sulawati, Linda T. (2017). Perilaku Altruis Relawan Organisasi AbdA di Tinjau dari Tingkat $E Q$ dan $S Q$. Skripsi. Jawa timur: IAIN Sunan Kalijaga

Syarif, Andi F. (2015). Altruisme Ditinjau dari Bystander Effect dan Jenis Kelamin pada 
e-Journal Keperawatan (e-Kp), Volume 7 Nomor 1, Mei 2019

Mahasiswa PPKN Fakultas Ilmu Sosial Universitas Negeri Makassar. Skripsi. Makassar: Universitas Negeri Makassar

Utomo, Yoga P. (2013). Hubungan Perilaku Agresi dengan Perilaku Altruisme pada Penikmat Musik Keras Usia Dewasa Awal. Skripsi. Yogyakarta: Universitas Sanata Dharma

Widyastuti, Fery. (2014). Hubungan antara Syukur dengan Perilaku Altruistik pada Mahasiswa Jurusan Tasawuf dan Psikoterapi angkatan 2012 Fakultas Ushuluddin IAIN Walisongo Semarang. Semarang: IAIN Walisongo

Wulandari, Veronica. (2011). Hubungan antara Kecerdasan Spiritual dengan Altruisme pada Anggota Komunitas San't Egidio Yokyakarta. Skripsi. Yokyakarta: Universitas Sanata Dharma

Zohar, Danah \& Marshall, Ian. (2007). Kecerdasan Spiritual (SQ) Memanfaatkan Kecerdasan Spiritual Dalam Berpikir Integralistik dan Holistik Untuk Memaknai Kehidupan. Bandung: Mizan 